\title{
Correspondence
}

\section{Response to Oderberg}

SIR

David Oderberg's letter (1) does little more than repeat the assumption I sought to challenge in Biological processes and moral events (2). Apart from repeating the point at issue, he complains that my conclusion should have been the premise of an argument I did not provide (a complaint that amounts merely to castigating me for not having written a different article altogether).

The central issue can be put as follows. The Australian Senate Select Committee (3) inquired into putative 'marker events' in the development of the human embryo. The purpose of the marker, could it be found, would be to determine the bounds of legitimate destructive experimentation. Finding only continuous processes in the biological development of the embryo, the committee concluded that there could be no such marker, and that therefore experimentation on human embryos could not be justified.

Mr Oderberg is quite right to insist that what the committee sought was a moral boundary, and that such a search did not commit them to the view that where there are processes there cannot be events. He is quite wrong, however, to suppose that this goes any way towards meeting my point.

The committee's view was that the continuity of the processes of early human development precluded the possibility of a moral marker. Why should this be so? I considered two possibilities: the first was that they were muddled about the relationship between processes and events, the second that any attempt to discriminate along a continuum would be arbitrary. I then showed that both these possibilities failed to do the job. Thus I did not argue that the committee was committed to a mistaken view about processes and events, but that that mistaken view was one way of explaining why they had come to the moral conclusion they had. I concluded by pointing out that I had not shown where, if anywhere, moral boundaries could be drawn, and that that issue could be settled only by invoking substantive moral beliefs. For Mr Oderberg to complain that I did not offer an argument for a particular boundary is thus quite irrelevant, and even suggests that he understands no form of moral debate which is (in the Kantian sense) critical rather than dogmatic.

Mr Oderberg concludes with a serious factual error in stating that syngamy takes fifteen days and not around one day. However, it now appears that this was due to a misprint in his letter so I won't pursue it. *

The central question remains to be answered: Why should continuity rule out morally significant boundaries? Continuity does not itself imply that all changes are equally morally important. This is not difficult to argue, and indeed I suggested as much in my penultimate tootnote: 'while it is certainly true that every stage in the embryo's development is equally necessary for that development to come to fruition, it is not therefore true that every stage is equally important. Morally speaking, the stage at which the brain is formed would seem to count for more [ie to make more of a moral difference] than the stage at which the fingers or other external features are formed, even though the brain cannot be formed without the successful prior completion of the earlier stages'.

Issues in which continuity plays a significant part are notoriously difficult to handle (as evidenced by the various paradoxes of motion). So it is not surprising that they bedevilled the committee, and continuc to bemuse others. Nevertheless, it is not true that discrimination, including moral discrimination, along continua is impossible. The vital moral task is to determine just which discriminations are defensible.

\section{References}

(1) Oderberg D. Foumal of medical ethics 1989; 15:166.

(2) Buckle S. Fournal of medical ethics 1988; 14:144-147.

(3) Senate Select Committee on the Human Embryo Experimentation Bill 1985. Human embryo experimentation in Australia. Canberra: Australian Government Publishing Service, 1986.

STEPHEN BUCKLE Centre for Human Bioethics, Monash University, Clayton, Victoria 3168 Australia.

\section{Correction}

*It was due to a misprint on the part of the journal that 'fifteen days' and not 'one full day' was published in $\mathbf{M r}$ Oderberg's original letter as the time taken for syngamy to occur. We apologise most sincerely for the error and resulting confusion.

\section{Organ donations}

SIR

It was interesting to read the article Organ donations should not be restricted to relatives, in the March 1989 edition of the journal, (pages 1720) and its corollary, Briefings in Medical Ethics, published in April 1989.

Both discuss the morality of nonrelated kidney donors, both seem to relate this only to payment for organs. They ignore the fact that not all nonrelated prospective donors are potential sellers.

Altruism is praised in both papers, the first quoting from the Council of Europe's first Report on Organ 
Transplantation: 'Everyone will agree that organ donation is one of the finest gestures of fraternity and love of which man [sic] is capable'. Presumably such altruism applies equally to friends as to relatives, another form of non-relative who would perhaps be willing to make such a donation for free. After all, friends sometimes act as surrogate mothers, another risk procedure.

The problem here is that a friend today is not necessarily a friend tomorrow, and the strains of the gift relationship could sever such a relationship (as indeed sometimes happens in the case of sibling donors).

But I am concerned that the whole argument about kidney donation is to do with the health of the recipient. The discussions about donors are to do with the 'altruism' of the related donor and the morality of accepted payment for an organ.

What about the morality of accepting an organ from a relative, friend or unknown donor? There are risks in any major operation, risks from the anaesthetic, from post-surgical complications, and from a donor later developing a renal disease. No matter how slight the risks, they are there and they are unnecessary. The operation will always be performed on a perfectly healthy person who, if related - as is pointed out in both articles - is likely to have considerable social pressure (even if only implicit) to donate and would suffer guilt if he or she did not do so.
There is nothing in any of the declarations on organ donation which makes any statement about the morality of one person allowing another to take the risks, to undergo the discomfort and possibly to die in order to prolong the recipient's life.

It is in order to lay down one's life for another. Surely it is not in order to ask someone to do it for you.

Morality, it seems to me, is taking quite a battering.

VIVIANNE DE VAHL DAVIS, PHD

Visiting Faculty, Center for the Study of Bioethics, Medical College of Wisconsin, (From the Faculty of Humanities, University of Technology, Sydney). 


\section{Correspondence}

\section{Response to Oderberg}

SIR

David Oderberg's letter (1) does little more than repeat the assumption I sought to challenge in Biological processes and moral events (2). Apart from repeating the point at issue, he complains that my conclusion should have been the premise of an argument I did not provide (a complaint that amounts merely to castigating me for not having written a different article altogether).

The central issue can be put as follows. The Australian Senate Select Committee (3) inquired into putative 'marker events' in the development of the human embryo. The purpose of the marker, could it be found, would be to determine the bounds of legitimate destructive experimentation. Finding only continuous processes in the biological development of the embryo, the committee concluded that there could be no such marker, and that therefore experimentation on human embryos could not be justified.

Mr Oderberg is quite right to insist that what the committee sought was a moral boundary, and that such a search did not commit them to the view that where there are processes there cannot be events. He is quite wrong, however, to suppose that this goes any way towards meeting my point.

The committee's view was that the continuity of the processes of early human development precluded the possibility of a moral marker. Why should this be so? I considered two possibilities: the first was that they were muddled about the relationship between processes and events, the second that any attempt to discriminate along a continuum would be arbitrary. I then showed that both these possibilities failed to do the job. Thus I did not argue that the committee was committed to a mistaken view about processes and events, but that that mistaken view was one way of explaining why they had come to the moral conclusion they had. I concluded by pointing out that I had not shown where, if anywhere, moral boundaries could be drawn, and that that issue could be settled only by invoking substantive moral beliefs. For Mr Oderberg to complain that I did not offer an argument for a particular boundary is thus quite irrelevant, and even suggests that he understands no form of moral debate which is (in the Kantian sense) critical rather than dogmatic.

Mr Oderberg concludes with a serious factual error in stating that syngamy takes fifteen days and not around one day. However, it now appears that this was due to a misprint in his letter so I won't pursue it. *

The central question remains to be answered: Why should continuity rule out morally significant boundaries? Continuity does not itself imply that all changes are equally morally important. This is not difficult to argue, and indeed I suggested as much in my penultimate tootnote: 'while it is certainly true that every stage in the embryo's development is equally necessary for that development to come to fruition, it is not therefore true that every stage is equally important. Morally speaking, the stage at which the brain is formed would seem to count for more [ie to make more of a moral difference] than the stage at which the fingers or other external features are formed, even though the brain cannot be formed without the successful prior completion of the earlier stages'.

Issues in which continuity plays a significant part are notoriously difficult to handle (as evidenced by the various paradoxes of motion). So it is not surprising that they bedevilled the committee, and continuc to bemuse others. Nevertheless, it is not true that discrimination, including moral discrimination, along continua is impossible. The vital moral task is to determine just which discriminations are defensible.

\section{References}

(1) Oderberg D. Foumal of medical ethics 1989; 15:166.

(2) Buckle S. Fournal of medical ethics 1988; 14:144-147.

(3) Senate Select Committee on the Human Embryo Experimentation Bill 1985. Human embryo experimentation in Australia. Canberra: Australian Government Publishing Service, 1986.

STEPHEN BUCKLE Centre for Human Bioethics, Monash University, Clayton, Victoria 3168 Australia.

\section{Correction}

*It was due to a misprint on the part of the journal that 'fifteen days' and not 'one full day' was published in $\mathbf{M r}$ Oderberg's original letter as the time taken for syngamy to occur. We apologise most sincerely for the error and resulting confusion.

\section{Organ donations}

SIR

It was interesting to read the article Organ donations should not be restricted to relatives, in the March 1989 edition of the journal, (pages 1720) and its corollary, Briefings in Medical Ethics, published in April 1989.

Both discuss the morality of nonrelated kidney donors, both seem to relate this only to payment for organs. They ignore the fact that not all nonrelated prospective donors are potential sellers.

Altruism is praised in both papers, the first quoting from the Council of Europe's first Report on Organ 